\title{
Asian Alterity
}

With Special Reference to

Architecture + Urbanism through

The Lens of Cultural Studies

William 5 W Lim 


\section{About the author}

William 5 W Lim graduated from the Architectural Association (AA) London and continued his graduate study at the Department of City and Regional Planning, Harvard University. Lim is a citizen of the Republic of Singapore. His professional work involves architecture, planning and development economics. He was principal architect at Malayan Architects [o-Partnership from 1960-1967, Design Partnership (later renamed DP Architects) from 1967 to 1981, and William Lim Associates from 1981 to 2002.

Lim is president of AA Asia and co-founder and chairman of the Asian Urban Lab (2003). He was also president of the Singapore Heritage Society from 1988 to 1997, and of the Singapore Planning and Research Group (5PUR) from 1966 to 1968. Presently, Lim is Adjunct Professor of the Royal Melbourne Institute of Technology (RMIT) University, Australia, and Guest Professor of Tianjin University, China. Lim was conferred a Doctor of Architecture Honoris [ausa by RMIT University in 2002 and Honorary Professor of LaSalle-5IA College of the Arts (Singapore) in 2005.

Currently, Lim writes and lectures on a wide range of subjects relating to architecture, urbanism and culture in Asian cities as well as on current issues relating to the postmodern, glocality and social justice.

Lim is the author of the following books:

Architecture, Culture, Ethics - A Workshop in NUS (2006) (Lee Kah Wee ed.)

Contesting Singapore's Urban Future [2006)

Asian Ethical Urbanism: A Radical Postmodern Perspective [2005]

Architecture, Art, Identity in Singapore: Is There Life after Tabula Rasa? (2004)

Have You Been Shanghaied? Culture and Urbanism in Glocalized Shanghai [2003]

Alternative (Post)modernity: An Asian Perspective [2003]

Alternatives in Transition: The Postmodern, Glocality and Social Justice [2001]

Asian New Urbanism [1998)

Contemporary Vernacular: Evoking Traditions in Asian Architecture, c0-authored with Tan Hock Beng (1997)

Cities for People: Reflections of a Southeast Asian Architect [1990)

An Alternative Urban Strategy [1980]

Equity and Urban Environment in the Third World [1975]

\section{About the designer}

Jackson Tan is co-founder of Black Design, an award winning visual communications agency based in Singapore. Black specializes in branding,design and design content development. He has worked with brands such as Discovery Channel, MTV, Diesel, Nike and Daimler Chrysler. In 2004, He was commissioned by DesignSingapore [ouncil to conceptualize, curate and design a highly successful landmark exhibition called 20/20. It is an ongoing showcase of 20 of Singapore's finest creative talents and charts the paradigm shifts that has occurred within Singapore's creative landscape. 


\title{
Asian Alterity
}

With Special Reference to Architecture + Urbanism through The Lens of Cultural Studies

\author{
William 5 W Lim Forewords by \\ Andrew Lee + Leong Teng Wui \\ Linda Lim \\ Lim Teck Ghee
}


Published by

World Scientific Publishing [o. Pte. Ltd.

5 Toh Tuck Link, Singapore 596224

USA office: 27 Warren Street, Suite 401-402, Hackensack, NJ 07601

UK office: 57 Shelton Street, Covent Garden, London W[2H 9HE

Library of Congress Cataloging-in-Publication Data

Lim, William Siew Wai, 1932-

Asian alterity : with special reference to architecture and urbanism through

the lens of cultural studies / by William 5.W. Lim ; Forewords by Andrew Lee ... [et al.]. -- 1st ed.

p. cm.

Includes bibliographical references and index.

ISBN 978-981-277-107-0 (alk. paper) -- ISBN 978-981-270-771-0 (alk. paper)

1. Architecture and society--Asia. 2. Urbanization -- Asia.

3. City and town life--Asia--Cross-cultural studies.

4. Cities and towns--Asia--Growth--[ase studies. I. Title.

NA2543.56L55 2008

$720.95--d c 22$

British Library [ataloguing-in-Publication Data

A catalogue record for this book is available from the British Library.

[opyright [ 2008 by William Lim Siew Wai

All rights reserved.

Printed in Singapore by Mainland Press. 


\section{THIS BOOK IS DEDICATED TO THE MILLIONS OF URBAN POOR IN THE ASIAN EMERGING ECONOMIES WHO DESERVE AN EQUITABLE SHARE OF THE DEVELOPMENT BENEFITS}





\section{CONTENTS}

008 ACKNOWLEDGEMENTS

010 OUTLINE OF BOOK

\section{PART I ASIAN ALTERITY}

015 NOTE ON FOREWORD WRITERS AND REVIEWERS

016 FOREWORDS

Andrew Lee and Leong Teng Wui

Linda Lim

Lim Teck Ghee

Selected Quotes from Reviewers

033

036

042

048

052

056

066

074

080

083

090

096

100

104

112

144

184 WHAT OTHERS SAY

CHAPTER 1 INTRODUCTION AND THE RISE OF ASIA

Introductory Notes

The Relevance of Cultural Studies

The Rise of Asia

\section{CHAPTER 2 MODERNITIES}

Multiple Modernities and Contemporariness

Democracy, Human Rights and Social Justice

CHAPTER 3 SELECTED CULTURAL STUDIES

Cultural Identities, Diasporas and Memories

Globalization and Inequalities

Sustainability and Affordability

Popular Culture and the Contemporary

CHAPTER 4 ASIAN ARCHITECTURE AND URBANISM

Creativity of the Contemporary

Asian Urbanism - Challenges Ahead

Asian Architecture - Challenges Ahead

Ryan Bishop

Iain Borden

Chua Beng Huat

Cui Kai

Randolf 5 David

Hsia Chu-Joe

Kenneth Frampton

Sumet Jumsai

Rahul Mehrotra

John W P Philips

Saskia Sassen

Sharon Siddique

Edward W Soja

Michael Sorkin

Zhu Jianfei

\section{PART II CASE STUDIES OF ASIAN CITIES}

002 INTRODUCTION

William 5 W Lim

OO4 COMMENTS ON WORKSHOP

Chua Beng Huat

008 BANGKOK: A CITY IN FLUX

Kanika R'kul (Ratanapridakul)

O20 HO CHI MINH CITY (SAIGON):

BEFORE THE DOORSTEP OF GLOBAL ASSIMILATION Tran Khang

028 HONG KONG: CITY OF MAXIMUM QUANTITIES Li Shiqiao

037 ISTANBUL: OBSERVATIONS

Tan Kay Ngee

046 THE MELBOURNE CASE STUDY:

THE CONSULTANT ARRIVES (AND SEES)...

Leon van Schaik

0058 SEOUL: GANGNAM ALTERNATIVE NATURE THE EXPERIENCE OF NATURE WITHOUT PARKS Yoon-Jin Park and Jungyoon Kim

0068 SHANGHAI ASSESSED: SIX ARCHITECTURAL NODES OF THE CITY Eunice Seng, Wee H Koon, Soh E Keat

080 SINGAPORE: IN SEARCH OF TRANSPARENCY Kaw Jon Kher

088 TOKYO: AN URBAN COLLAGE OF CHAOS AMIDST ORDER Takeo Muraji

205 ENDNOTES

214 WORKS CITED

218 INDEX

222 IMAGE CREDITS 


\section{Acknowledgements}

Asian Alterity with special reference to Architecture and Urbanism through the Lens of Cultural Studies started off with the objective of developing comprehensive in-depth theoretical and analytical studies to address the Asian urban condition. I would like to convey my deep appreciation to Leon van Schaik for his encouragement, in particular his letter of recommendation which supported Asian Urban Lab's application to obtain a research grant from Lee Foundation in March 2006. I must record my gratitude to Lee Foundation for their generous financial support. In addition, I must extend my appreciation to Professor K K Phua and Ms Doreen Liu of World Scientific Publishing [o. for the indication of their confidence in me, by agreeing at the initial stage of research to undertake the publishing and promotion of the book.

Asian Alterity requires an innovative and interdisciplinary approach in its content and structural arrangements. As the research proceeds, the book has been restructured, expanded and revised. The wide-ranging subjects and analysis discussed in the book are substantially enriched by my direct communication with numerous scholars and academics and the many insightful and stimulating theories and ideas available in many current publications and articles.

I wish to express my gratitude for the invaluable comments and support from Sharon Siddique who has continuously reviewed and provided incisive comments to the contents of the book; Leon van Schaik for his invaluable input on key issues; Chua Beng Huat for reviewing and commenting on the manuscript of Part I; and my research assistant, Lim Shujuan whom had worked closely in providing research materials as well as being involved in the book's overall production co-ordination.

As the research and writing of Asian Alterity develop, the idea to expand its scope by illustrating selected Asian cities by different writers emerged. I am delighted to receive encouraging and positive response. I wish here to thank the invaluable and exciting contributions of the following writers of the case studies:- Bangkok by Kanika R'kul(Ratanapridakul); Ho Chi Minh City by Tran Khang; Hong Kong by Li Shiqiao; Istanbul by Tan Kay Ngee; Melbourne by Leon van Schaik; Seoul by Yoon-jin Park and Jungyoon Kim; Shanghai by Eunice Seng, Wee H Koon and Soh E Keat; Singapore by Kaw Jon Kher ; and Tokyo by Takeo Muraji. I must also thank Chua Beng Huat and Hsia Chu-Joe for conducting and facilitating the workshop for the city case studies in late July 2007.

In February 2007, I communicated with DesignSingapore Council to obtain additional financial support. While the Council is sympathetic, it is felt that their support should be directed towards the quality of design and presentation of the book. Asian Urban Lab wishes to thank DesignSingapore Council for granting a generous sponsorship to support the appointment of Jackson Tan, a leading graphic designer in Singapore, for this specific assignment. 
At the meantime, due to the expanded scale of the book, substantial funding is needed to cover the additional costs for the case studies and to complete the expanded research. I have decided to appeal to several local institutions, friends and professional colleagues for their financial support. The response has been overwhelming. Asian Urban Lab wishes to acknowledge the generous contributions and support from Ernesto Bedmar of Bedmar \& Shi Pte Ltd; Sonny Chan of Chan Sau Yan Associations; Chan 500 Kian of 5CDA Architects Pte Ltd; Chan Sui Him of DP Architects Pte Ltd; Edmund Cheng of Wing Tai Property Management Pte Ltd; Rifaat El Gohary of Bakri Trading [o. (Asia) Pte Ltd; Richard Hassell and Wong Mun Summ of WOHA Pte Ltd; Winston Hauw of Rider Levett Bucknall Pte Ltd; Housing Development Board; Iqal Jumabhoy of Edge Capital Pte Ltd; Sat Pal Khattar; Kok Siew Hoong; Kwee Liong Seen of Pontiac Marina Pte Ltd; Charles Letts; Lim Teng Ngiom; Fumihiko Maki of Maki and Associates; Franklin Po of Tierra Design (5) Pte Ltd; Jackson Tan and Patrick Gan of Black Design Pte Ltd; Temasek Holdings Pte Ltd; Edmund Tie of DTZ Debenham Tie Leung (SEA) Pte Ltd and Wee Chwee Heng.

Asian Urban Lab also wishes to specially thank the generous contributions of Lee Foundation and DesignSingapore Council as well as Temasek Holdings Pte Ltd; Chan Sui Him of DP Architects Pte Ltd; Housing Development Board; and Kwee Liong Seen of Pontiac Marina Pte Ltd.

I must extend my deep appreciation to Andrew Lee/Leong Teng Wui; Linda Lim and Lim Teck Ghee who have all written insightful forewords that give readers a deeper understanding and interpretation of the book. I wish also to thank the following reviewers for their short and penetrating comments. They are Ryan Bishop; Iain Borden; Chua Beng Huat; [ui Kai; Randolf 5 David; Kenneth Frampton; Hsia Chu-Joe; Sumet Jumsai; Rahul Mehrotra; John W P Philips; Saskia Sassen, Sharon Siddique; Edward Soja; Michael Sorkin; and Zhu Jianfei.

I must say thank you to Ms Doreen Liu and her staff members of World Scientific Publishing Co. for their efforts towards the marketing and publishing of this book as well as Jackson Tan for his innovative design and layout. I would also like to acknowledge Andrew Lee for his professional advice in particular the selection of appropriate architectural illustrations. In addition, I must also extend my appreciation to Sun-chang Lo for granting permission to publish his delightful sketches, and the many architects for their collaboration in producing examples of their works as well as my personal secretary, Patricia Lee for her continuous support.

Last but not least, I wish to thank my wife, Lena, for being the perpetual commentator and critic of all my writings for more than three decades.

\section{Prof. William 5 W Lim \\ Chairman of Asian Urban Lab Ltd}




\section{Outline of Book}

Asian Alterity with Special Reference to Architecture and Urbanism through the Lens of Cultural Studies consists of two parts. Alterity is defined by the Webster dictionary as "the state or quality of being other".

Part I is a continuation of my research on Asian urbanism following my prior publications Asian New Urbanism (1998) and Asian Ethical Urbanism (2004). Asian Alterity is an interdisciplinary theoretical analysis that vigorously contests the homogeneity of the mainstream Eurocentric values. It argues for an alternate perspective to be introduced in order to understand the diversity of the Asian countries' cultural differences at various development stages and to meet the complex challenges of the explosive urban expansion and disruptive changes in traditional cultures and lifestyles.

Chapter 1, "Introduction" consists of three sections: "Introductory Notes", "The Relevance of Cultural Studies", and "The Rise of Asia". "Introductory Notes" places the theoretical analysis in context by examining the reasons for the importance of understanding Asian urbanism. The second section, "The Relevance of Cultural Studies", argues for the necessity of introducing broader perspectives in order to understand Asian urbanism beyond traditional discipline-focused discourses to keep pace with the rapid changes generated by globalization, information and communications technology (ICT) and the rise of emerging economies in Asia. As there is presently a serious paucity of interdisciplinary discourses in Asia, the field of cultural studies is essential for providing a bridge that connects theoretical discourse to the everyday challenges. Its interdisciplinary mode is particularly apt for providing a broadening perspective in interpreting issue-oriented and disciplinespecific issues, as well as uncovering plural and alternate discourses and allowing them to arise. The third section, "The Rise of Asia", uncovers painful early struggles in Asian countries to achieve modernity. It traces the notable success in recent decades of Asia's rapidly emerging economic development in selected countries and in their contest with the present Western economic development models by developing credible indigenous responses. The section concludes that the entire centre-periphery structure of the present global economy will be subverted, and that the world as we know it now will soon be dramatically changed, both politically and culturally.

Chapter 2, "Modernities", consists of two sections: "Multiple Modernities and Contemporariness" and "Democracy, Human Rights and Social Justice". The first section, "Multiple Modernities and Contemporariness", questions the homogeneity and universalism of Eurocentric modernity, besides exposing the inherent power relations embedded within it. It argues that many of the universalistic assumptions of Eurocentric modernity are no longer viable paradigms for the non-West to understand contemporary society. Instead, the notion of multiple modernities, which is a pluralistic approach that takes into account the rich, diverse cultural essences of the non-West, would reclaim the historical legitimacy of their indigenous modernity. This is elaborated in comments on "China's Modernity" and "Islamic Modernity". The contemporariness of multiple modernities is highlighted in the subsection, "The Everyday World". In identifying five vital contemporary forces which have contributed extensively to rapid changes, it strongly argues that in a world of multiple modernities, different starting points for the transition to contemporary modernity will lead to different outcomes. These five forces are: new knowledge, information and communications technology (ICT), globalization, new politics, and civil society organizations ([50s). In today's frenetic pace of life, where the only constant is change, creative adaptation and response is essential. It is a turbulent site where the homogenizing and alienating force of globalization and neo-liberal capitalism with their boundless greed for power and money, 
as well as excessive consumption, need to be constantly regulated and contested by applying the positive spirit of core values embedded within local cultures and traditions.

The second section, "Democracy, Human Rights and Social Justice", illustrates the applicability of multiple modernities. The subsection "Democracy" examines three Asian interpretations of the Western democratic form - the Philippines, Thailand and Singapore - and shows how alternative applications, values and visions of democracy emerge in the context of different cultural traditions. The subsection "Human Rights and Social Justice" identifies the importance of the theory of multiple modernities in providing a firm anchorage for the non-West to pursue their own priorities in the context of rapidly changing conditions. In the last two decades, the dominance of the Western-centric paradigm in human rights and social justice has been seriously challenged. Provision of basic needs for all citizens and reduction of income disparity between and within countries are now given increasing attention.

Chapter 3, "Selected Cultural Studies", examines the relevance of specific current cultural studies with radical knowledge that have important bearings on contemporary values and cultures, as well as on architecture and urbanism in Asia. The issues discussed are: "Cultural Identities, Memories and Diasporas", "Globalization and Inequality", "Sustainability and Affordability" and "Popular Culture and the Contemporary". The first section, "Cultural Identities, Memories and Diasporas", examines the complexities of cultural identity formation and recognizes that each person can have and can be enriched by multiple, at times conflicting, identity positions. It stresses the need to adopt an inclusive attitude towards multiculturalism, particularly for diaspora communities, and the important link of collective memories to the sense of belonging to the community. The second section, "Globalization and Inequalities", argues that the current income disparity generated by neoliberal globalization is not inevitable. It recognizes that to achieve continuous high rates of growth together with broad social-oriented community objectives of justice and income equity is a tough road to travel. Each country must chart its own strategy and find its own solution. The third section, "Sustainability and Affordability" poses some hard questions: Sustainability for whom? Who benefits and who loses? It argues for the essentiality of providing at affordable cost basic urban facilities such as housing, healthcare and transport to the majority. The challenge for architecture and urbanism is to investigate and apply unfamiliar ground rules in order to find alternative solutions which will undoubtedly generate new and unexpected urbanscapes and design possibilities. The fourth section, "Popular [ulture and the Contemporary", describes the evolution of popular culture from folk culture to the mass-media dominated contemporary. The dichotomous struggle between creative art production and mass market consumerism continues unabated. Recent intrusive contributions from the non-West have generated many new challenges, including the popular canon-mocking post-totalitarian society in China today.

Chapter 4, "Asian Architecture and Urbanism", consists of three sections: "Creativity of the Contemporary", "Asian Urbanism - Challenges Ahead", and "Asian Architecture - Challenges Ahead". The first section, "Creativity of the Contemporary" focuses on the importance of creativity and the characteristics of the creative environment. Three essential forces and vital elements that will contribute to the development of a creative contemporary society and generate a broad-based new paradigm for understanding creativity are examined. They are "the tipping point", "new knowledge" and "criticality". The second section, "Asian Urbanism - Challenges Ahead", examines the challenges confronting Asian cities today. In particular, the problems of the frenetic pace of economic expansion and the accelerating rate of urbanization are addressed. 
In combating these problems, the package of ethical instruments which I had previously identified in Asian Ethical Urbanism (2004) is expanded. In addition to the previous five ethical instruments - conservation and memories; safeguarding the commons; spaces of indeterminacy; land policy and spatial justice - two social-oriented urban instruments are included. These are urban transport and provision of basic needs to the poor. I argue that the incorporation of these ethical instruments are essential for reorienting the governing principles of policy-makers away from the elite-oriented profit maximization, towards ensuring a more equitable society and a better quality of urban life for all. Lastly, selected Asian examples of creative and innovative urban instruments that interpret contemporary lifestyles and blend them with local cultural traditions and peculiarities are examined. The key themes are: the historic present; chaotic order, cuttingedge urban instruments, and kinetic cities. These innovative urban actions fuel the vibrancy and dynamism of Asian cities by introducing exciting creative city-specific instruments as well as by identifying the challenges of kinetic cities to establish an essential partnership with the bazaar-like squatter settlements. The third section, "Asian Architecture — Challenges Ahead", examines firstly the problems confronting Asian architecture today, in particular the issue of a colonial hangover, the unquestioning adoption of Modernism, generic architecture and the culture of greed. Secondly, solutions for meeting contemporary challenges are examined. Issues include the need to integrate traditions with contemporary lifestyles and the need to foster a criticality looking beyond the traditional boundaries of its field through the lens of cultural studies and multiple modernities. Lastly, eight Asian architectural projects are selected for their resistance to the homogenizing force of globalization and the overwhelming impact of generic architecture. Three key themes are: cultural rootedness, contemporary vernacular, and contending contemporary challenges.

The current urban theories are unable to provide clear directions or satisfactory solutions for dealing with the dramatic changes and challenges of explosive urban growth in Asia, as well as the missed opportunities of architectural creation. Furthermore, because of the explosion of knowledge, together with the dramatic changes in values and lifestyles, the future in the long run is clearly uncertain. The ruthless pursuit of linear economic growth and the culture of greed may be the worst price to pay for our consumer-oriented utopian dreams. Asian Alterity has identified key issues, such as ethical urbanism, a post-planning development model, partnering squatter settlements in kinetic cities and challenging the generic environment, etc., which have thrown some light in the formulation of interdisciplinary approaches to the numerous challenges of income distribution, human rights and social justice confronting urban Asia today. 
Part II of the book consists of nine case studies of major Asian urban cities by well-established academic writers and urban theorists. These cities are selected because of the diversity of their development stages and the vast differences in their political and economic systems as well as their complex cultural and urban traditions. A two-day workshop was held in July 2007 for the writers to present their personal perspectives on the diverse aspects of the engines of dynamism of their cities. They engaged in critical discussion and commentary, which that deepen the analysis of the writings.

The titles of the case studies are: "Bangkok: A City in Flux" by Kanika R'kul (Ratanapridakul); "Ho Chi Minh City Before the Doorstep of Global Assimilation" by Tran Khang; "Hong Kong: City of Maximum Quantities" by Li Shiqiao; "Istanbul Observations" by Tan Kay Ngee; "The Melbourne Case Study: The Consultant Arrives (and Sees)..." by Leon van Schaik; "Seoul: Gangnam Alternative Nature - The Experience of Nature Without Parks" by Yoon-Jin Park and Jungyoon Kim; "Shanghai Assessed: Six Architectural Nodes of the City" by Eunice Seng, Wee H. Koon and Soh E. Keat; "Singapore: In Search of Transparency" by Kaw Jon Kher and "Tokyo: An Urban Collage of Chaos Amidst Order" by Takeo Muraji. These case studies will collectively broaden the framework of my thesis in Part I, as well as demonstrate aspects of the interdisciplinary mode of cultural studies as an important lens with which to meeting the challenges in Asian architecture and urbanism. The diverse approaches and interpretations of the writers uncover a dynamic kaleidoscopic mosaic of Asian cities. 


\section{Asian Urban Lab}

Asian Urban Lab is a Singapore-registered non-profit company founded in 2003 with three primary objectives. First, to promote a greater awareness and understanding of contemporary urban issues in Asia; second, to facilitate multidisciplinary research and discussion on topics related to the trends and directions of modern Asian urban life and architecture; and third, to disseminate the results of this research to as broad an audience as possible.

In order to realize these objectives, research on topics related to contemporary Asian urban life is commissioned by Asian Urban Lab. Asian Alterity with special reference to Architecture and Urbanism through the Lens of Cultural Studies is the Lab's fourth publication. Other publications commissioned by Asian Urban Lab include: Contesting Singapore's Urban Future (2006), Architecture, Art, Identity in Singapore - Is there Life after Tabula Rasa?(2004) and Have you been Shanghaied: Culture and Urbanism in Glocalized Shanghai(2004).

Asian Urban Lab also plans to organize workshops and seminars on topics related to contemporary Asian urban life. Materials presented at such gatherings will be published whenever possible. Independent research by individuals will also be encouraged.

At present, the company has two directors, Professor William 5. W. Lim, who serves as Chairman and Dr Sharon Siddique. Both have published widely on Asian urban topics. They are responsible for overseeing the activities, and ensuring that projects which are undertaken or endorsed by the Asian Urban Lab are in line with the Lab's objectives.

Asian Urban Lab has also tapped the expertise of leading Asian specialists on urban studies and architecture, through their appointments to the Advisory Board. Presently, members of the Advisory Board of Asian specialists include Professor Chua Beng Huat (Singapore), Professor Randolf 5. David (Philippines), Professor Hsia Chu-Joe (Taiwan), Dr Sumet Jumsai (Thailand), Dr Arthur Lim (Singapore), Professor Li Shiqiao (Hong Kong/China), Professor Fumihiko Maki (Japan), Associate Professor John W P Philips (Singapore), Professor Wang Gungwu and Professor Leon van Schaik (Australia). 